were detached for about an inch around the opening made by the ball, which was then enlarged by the chisel and some pieces of bone removed. The projectile was now found firmly fixed in the cancellous tissue. By means of a pair of toothed forceps the bullet was speedily seized and withdrawn. A probe could now be passed into the interior of the bone for a distance of exactly $2 \frac{1}{2}$ in. from its surface, and the extremity must have reached nearly to the external aspect of the external condyle, while the bullet track could certainly not have been, at all events in some parts of its course, more than a quarter of an inch distant from the articular surface of the end of the femur. A double drainagetube having been introduced, the wound was syringed out with carbolic acid solution of a strength of 1 in 40 . The edges of the divided tissues were brought together by silk sutures, and the wound dressed with iodoform gauze and salicylic wool. A narrow wooden splint curved to the shape of the limb was applied posteriorly, and strips of Bavarian flannel soaked in plaster-of-Paris were applied anteriorly and laterally, the limb being bandaged to the splint from the foot to about half-way up the thigh.

3rd.-The patient has had a good night. Last evening's temperature was $100.8^{\circ}$, and this morning it is $100.4^{\circ}$. A slight oozing came through last night and a fresh dressing was applied.

4th.-Temperature last night $1008^{\circ}$; this morning $99 \cdot 6^{\circ}$. Wound dressed. It is looking healthy. New plaster-of-Paris splints were applied, and the wooden one was removed.

11th.-Temperature last night $1002^{\circ}$; this morning $99^{\circ}$.

During the next week the patient did not complain of any pain, and he felt quite well. The temperature was normal. The stitches were removed on the 8th, when the wound was found to be united except in the position of the former sinus. The drainage-tube was gradually shortened as the bullettrack became filled with granulations. The patient got up on the 16th. From first to last he had little or no inconvenience. The joint under the influence of passive movements was becoming less swollen and supple, and he left for home on Nov. 28th, able to walk a long distance without the least difficulty. The sinus was quite superficial and on the point of closing. In a letter from Mr. LJan. 14th, 1886, he says: "I can do as much walking and riding now as $I$ ever did, and bend my right leg as far as the other." The bullet, of which a drawing is given in Fig. 4, was flattened somewhat at its extremity; it weighed 340 grains. A similar bullet, weighing 245 grains, is shown in Fig. 5, taken from an unexploded cartridge.

Remarks. - The two cases recorded are striking from the simllarity of the injury in each. The bullets causing the damage were almost alike in size, although one was discharged from a rifle and the other at close quarters from a pistol. The ball traversed the expanded portion of the condyles transversely in both cases from within outwards, in each instance very near to the articular surface, lodging in the bone in both, and in both remaining undiscovered for a considerable time. In both, too, there were symptoms of inflammation in the kneejoint, some pain, fever, swelling, and subsequent stiffness, which passed off. It is difficult to believe that in either the injury could have been wholly extra-articular. Conical bullets such as these, and capable of penetrating the bone to so considerable a depth, would be very likely to cause fissures which would almost certainly extend to the joint surface, while the continued presence of the foreign body could scarcely fail, one would suppose, to excite articular mischief. Nevertheless, in neither of these two cases has any permanent ill result followed, and the function of the joint is in both perfectly restored. There is a strong presumption, without, I admit, any positive proof, that the knee-joint was implicated to a greater or less degree in each of these cases, yet recovery has ensued with a freely movable articulation, and certainly without in either case any special advantage in regard to treatment. Perhaps, after all, a gunshot injury of the knee may not be always so disastrous as it was at one time assumed to be. Langenbeck told me he had met with at least one hundred cases of penetrating wound of the knee-joint followed by recovery during the Franco-German war. Many cases of recovery after a bullet had traversed the joint and fractured the bones are recorded by the Surgeon-General of the United States army; and then there are the remarkable results published by Bergmann and Reyher obtained after antiseptic occlusion in the Russo-Turkish and other campaigns. During the American war 338 cases of unmistakable frac- ture involving the bones of the knee-joint made good recoveries after an altogether expectant plan of treatmentthat is, both life and limb were preserved. Many of the cases besides the one which I have first quoted, are most remarkable, but for the details I must refer to the SurgeonGeneral's report. A conservative treatment, whenever it is possible to adopt it, is probably by far the most promising one for gunshot injury of the knee-joint, and it has proved the most successful, especially in recent campaigns. Excision of the knee for gunshot injury in time of war has hitherto been disastrous, while amputation has been very fatal also.

\section{SYMMETRICAL SYNOVITIS OF THE KNEE IN HEREDITARY SYPHILIS.}

\author{
BY H. H. CLUTTON,
}

ASSISTANT-SURGEON TO ST. THOMAS'S HOSPITAI.

THE fact that the condition of which the title of this paper gives the most prominent feature has been little noticed in our surgical literature tempts me to make a few remarks as to its clinical features. I have myself but little doubt that it is due to hereditary syphilis, for the subjects of this symmetrical synovitis who have come under my observation have always given other evidence, either past or present, of the disease. My own cases, of which the notes have been carefully kept, are seven in number. $\mathbf{M r}$. Nettleship, who has also taken a great interest in these cases, has kindly given me the notes of three others, which I have myself seen at the time they were under observation in the eye department at St. Thomas's Hospital. Mr. Lawford has ălso supplied me with another case during the last six months, which brings the total to eleven. 1 have, I am sure, seen many more of which I can find no accurate record; and I well remember, some years ago, soon after I began to take an interest in this subject, that $D r$. Greenfield, who was then my colleague, drew my attention to several cases which had occurred in his practice. It must be remembered that my own cases were all outpatients, one or two only being admitted for a time to test the efficacy of splints and rest. The difficulty of keeping any notes in the out-patient room must be my excuse for this deficiency. The disease is, I am sure, a rare one, so that only a few cases will come under the observation of any one surgeon; for since my attention has been directed to this condition I have been on the look out for such patients, and have only met with quite a small number.

The average age of the patients recorded in the accompanying table was about thirteen, but they were mostly between the ages of eight and fifteen. The predominant features of the disease were the symmetry of the affection, the freedom from pain, the long duration of the symptoms, and the free mobility of the joints on passive movement throughout the course of the disease. Its symmetrical character first led nie to look for a constitutional cause, and there was no difficulty in seeing that the patients were the subjects of hereditary syphilis. I do not mean to say that no other constitutional diseases could possibly have producec such a symmetrical condition, but I do think that other joints besides the knees would probably have been at some time and in some of the cases affected in a similar manner if such diseases as rheumatism, gonorrhcea, or gout had been the cause. I have never seen both knee-joints fill with fluid, causing scarcely any pain or discomfort, whilst other joints remain quite free from any signs of inflammation, except in cases where there was distinct evidence, either past or present, of hereditary syphilis. The patient generally complains of stiffness in one knee, which is then found full of fluid, but not tense: on careful examination the other knee is also found to contain fluid, but not to the same extent as the one for which advice is sought. So that it is fair to assume that the knee to which attention has been directed by the patient has been affected some little time before he has felt any inconvenience. In a few instances there has been an interval of some months before the second knee has given the ordinary signs of synovitis; and in one case (No. 5 in table), which was that of the patient aged twenty, there was an interval of two years. All the other joints have been at the same time carefully examined, to make 
sure that such an insidious chronic synovitis has not been overlooked, but no joint affection could at any time be discovered elsewhere; nor was there any history pointing in that direction in any of the cases which are here recorded, except in No. 11 in the table. The swelling in some of the cases was accompanied by considerable thickening of the synovial membrane; and in one instance (No. 8) recorded by Mr. Nettleship, the observation is made that in some places it gave the "impression of loose bodies in the joint." But in the greater number this swollen condition was not so noticeable a feature as in the synovitis which may occur as one of the later manifestations of the acquired disease. The chief part of the swelling in the cases now under consideration seemed to be produced by an increased quantity of synovial fluid. The joints were never tense, but gave a sensation of flaccid fluctuation, as if they were only half full of fluid. The bones in the immediate neighbourhood were not enlarged, and in only a small proportion of the cases was there any articular tenderness. Nodes were occasionally found, but generally some little time after the onset of the swollen joint and at some little distance from the affected articulation. The peculiarly chronic nature of were afflicted with absolute deafness of recent origin The latter symptom was in each case devoid of any other obvious cause, and must, I think, be attributed to hereditary syphilis. Thus, every one of the cases quoted had two or more of the symptoms which, taken together, may be fairly held to establish the presence of the disease in question. Less reliable symotoms, such as those presented by the features, have not been mentioned; but they existed in most of the children who came to the out-patient room with symmetrical synovitis of the knee. The family history is proverbially difficult to obtain in this department of the hospital, and although in a few instances it tended to confirm the opinion already formed, it may be stated generally to have been of a negative character. I do not think that this disease has any relation to epiphysitis, which is so common in syphilitic infants, for there was no apparent enlargement of the bone, as has been already stated, and the swelling was quite uniform in outline. In epiphysitis the swelling is always more or less unilateral, for although the whole joint may be enlarged by consecutive synovitis, one side will generally be found larger than the other, with increased tenderness on the side affected; whereas in the symmetrical synovitis, to

Eleven Cases of Symmetrical Synotitis of the KNeE.

\begin{tabular}{|c|c|c|c|c|c|c|}
\hline No. & Sex. & Age. & Joints. & $\begin{array}{l}\text { Duration } \\
\text { of symptoms. }\end{array}$ & Fvidence of hereditary syphilis. & Family history. \\
\hline 1 & M. & 10 & Both knees. & 4 months. & $\begin{array}{l}\text { Double interstitial keratitis ; typical teeth ; } \\
\text { ostitis of both tibir. }\end{array}$ & No notes. \\
\hline 2 & F. & 8 & Both knees. & 6 months. & $\begin{array}{l}\text { Double interstitial keratitis ; ostitis of one } \\
\text { tibia. }\end{array}$ & No history. \\
\hline 3 & M. & 11 & Both knees. & $\begin{array}{l}6 \text { weeks, and } \\
\text { then ceased } \\
\text { attending. }\end{array}$ & $\begin{array}{l}\text { One typical central incisor; nodes on tibiæ; } \\
\text { snuffles and skin eruptions in infancy. }\end{array}$ & $\begin{array}{l}\text { Mother had two stillborn } \\
\text { children before patient. }\end{array}$ \\
\hline 4 & $\mathbf{F}$. & 9 & Both knees. & 3 months. & $\begin{array}{l}\text { Interstitial keratitis of one eye of two weeks' } \\
\text { standing, with no further notes; one } \\
\text { typical central incisor. }\end{array}$ & No history. \\
\hline 5 & F. & 20 & Both knees (two years apart). & $\begin{array}{l}6 \text { months } \\
\text { each. }\end{array}$ & $\begin{array}{c}\text { Remains of double interstitial keratitis; } \\
\text { ostitis of both tibiæ, which are very large. }\end{array}$ & No history. \\
\hline 6 & F. & 10 & Both knees. & 7 months. & Double interstitial keratitis ; typical teeth. & $\begin{array}{l}\text { Father syphilitic; no evidence } \\
\text { in family beyond patient. }\end{array}$ \\
\hline 7 & F. & 15 & $\begin{array}{c}\text { Both knees, and right articular } \\
\text { tenderness. }\end{array}$ & 6 months. & $\begin{array}{l}\text { Double interstitial keratitis under } \mathrm{Mr} \text {. } \\
\text { Nettleship; incurable deafness of one } \\
\text { month's standing. }\end{array}$ & No history. \\
\hline 8 & M. & 14 & $\begin{array}{l}\text { Both knees, articular } \\
\text { tenderness. }\end{array}$ & 3 months. & Interstitial keratitis; typical teeth; deaf. & No notes. \\
\hline 9 & M. & 12 & Both knees. & $\begin{array}{l}2 \text { months, and } \\
\text { probably more. }\end{array}$ & Interstitial keratitis. & $\begin{array}{l}\text { Well-marked history of mother } \\
\text { being infected, and then } \\
\text { having miscarriages. }\end{array}$ \\
\hline 10 & $\mathrm{~F}$. & 8 & $\begin{array}{l}\text { Both knees acute and painful } \\
\text { one week after fall on knees. } \\
\text { One joint tapped. Recovered } \\
\text { with good joints. }\end{array}$ & 4 months. & Double interstitial keratitis. & Doubtful history. \\
\hline 11 & M. & 21 & $\begin{array}{l}\text { Both knees. History also of } \\
\text { both ankles having been } \\
\text { swollen at commencement. }\end{array}$ & 12 months. & $\begin{array}{l}\text { Double interstitial keratitis for nine months; } \\
\text { still under observation. }\end{array}$ & $\begin{array}{l}\text { Patient is third child; fourth, } \\
\text { fifth, sixth, and seventh } \\
\text { children died in infancy; } \\
\text { eighth under observation for } \\
\text { interstitial keratitis. }\end{array}$ \\
\hline
\end{tabular}

the synovitis is still further shown by the fact that in all the cases referred to in this paper the swelling has remained with scarcely any alteration for from three to six months, and in one instance for twelve months. In one case (No. 10) the symptoms followed a more acute course, but were distinctly attributed to a fall on the knees a week previously to the admission of the patient. Treatment by splints and rest in bed seemed to influence the course of the disease very slightly, for those that were treated in this way were as slow in getting well as those that had no local treatment whatever, for as soon as the splints were removed the effusion returned. The ultimate result in all the cases that came under my observation was the perfect recovery of the joints, the most important part of the treatment appearing to be the exhibition of antisyphilitic remedies-mercury and iodide of potassium; but these drugs had not the same marked effect that they have in the acquired disease.

The facts as to hereditary syphilis are as follows. Of the eleven cases, active keratitis was present in nine, and in one other the cornere bore traces of a former attack, so that in only one had the cornex escaped. Five had the central incisors marked in the manner characteristic of the disease. Four had nodes on the tibiæ, and two which allusion is here made, the joint is uniformly enlarged, and the synovial membrane appears to be the only part affected.

To recapitulate in a few words the principal features of the condition which was demonstrated by these few cases, one would say that the synovitis was symmetrical, affecting only the knees, that was of a chronic and painless character and that all the patients were the subjects of hereditary syphilis. I can offer no satisfactory explanation of the facts here recorded, but must content myself with drawing attention to a few clinical symptoms. At the same time I would like to point out that if the condition which is now under consideration be really due to hereditary syphilis, the similarity between interstitial keratitis and this symmetrica synovitis is so marked as scarcely to require any lengthened explanation. Both knees, like the eyes, are, in my experience, sooner or later affected, and often with an interval between the commencement of the symptoms in each joint Both diseases are exceedingly chronic, and produce little or no destructive changes in the tissues involved, neither suppuration nor adhesions having occurred in any of the cases that came under my observation. They are also both liable to relapses, and not very amenable to treatment. The age of the patients is another and striking point of similarity, for 
seven out of the eleven were between eight and twelve years of age. In two cases the symptoms arose at a much later date, but this also occurs in interstitial keratitis, so that even in its rarer forms it corresponds with that disease in this particular - that of the age of the patient. I am at a loss to explain why the knees should be affected in preference to other joints. It is probable that, with further observation, the knees will not be found to occupy this solitary distinction, and that other joints will be seen to be affected in a similar manner. But up to the present time I have not seen this chronic symmetrical synovitis, which appears to be associated with hereditary syphilis, in any other joints besides the knees. That it should be symmetrical is only what one expects from our knowledge of the similar manifestations of the disease at this period of life.

\section{THE NEUROTIC 'TREATMENT OF CATARRH.'}

BY DAVID B. LEES, M.A., M.D., F.R.C.P.,

PHYSICIAN TO OUT-PATIENTS, ST. MARY'S HOSPITAL; ASSISTANTPHYSICIAX, HOSPITAI FOR SICK CHILDREN.

ALTHOUGH by some writers the meaning of the word "catarrh" is extended to include various affections which are believed to have similar origin, the term is in itself simply a word-picture of that familiar complaint which the Greeks called "coryza," and which we know as a "cold in the head." Too familiar to most of us is this annoying condition. A severe cold hinders effective work for several days, makes the sufferer miserable while it lasts, depresses his vital energy, and sours his temper; it leaves him with an increased predisposition to take cold again. Nor is this all; it is too often the starting-point of chronic or even of acute disease. A formidable list might be made out of the sequelæ of catarrh; it would include chronic pharyngitis and enlarged tonsils, deafness from Eustachian obstruction and altered conditions of the tympanic membrane, mucopurulent collections in the middle ear, and in infants posterior basic meningitis leading to death or idiocy, chronic laryngitis with hoarseness, chronic bronchitis, and in neurotic subjects asthma, and last, but not least, through the permitted invasion of the tubercle bacillus, phthisis.

The present treatment of catarrh cannot be considered satisfactory. It rarely succeeds in cutting short the malady or in alleviating to any great extent its discomforts. It is essentially a diaphoretic treatment, insisting on confinement in warmed rooms, swallowing of hot liquids, and use of hot-water or vapour baths, or of the Turkish bath. The result aimed at by these various measures is diaphoresis; in plain English, the object is to arrest the flow from the nose by causing a flow from the skin. The reasonableness of this is about on a par with the action of one who should seek to have all the street lamps lighted in order to check the flow of gas into his house from a leak in his pipes; the plan might to some extent be successful, but we should not think highly of its wisdom, and should ask whether the tap had been turned at the meter. Can we in any way directly arrest the flow in catarrh? The answer to this depends upon a clear understanding as to its nature. If we ask the question, "What is catarrh essentially?" we must reply, "Catarrh is a neurosis, in which the vaso-motor system is largely concerned."

Nothing can be regarded as more certain than that the onset of catarrh is due, in a very large number of cases, to an impression of cold on the surface of the body, owing to draughts, insufficient clothing, or the chilling evaporation from damp clothes. An impression is made upon the cutaneous nerves, and is by them transmitted to the nerve centres. The effect is not immediately manifested, but after a few hours a general chilliness of the surface is experienced, clearly due to a general vaso-motor spasm of the cutaneous vessels, and accompanied by flying pains and aches in the limbs, which are probably really central and not peripheral, and due to disturbed vascular conditions of the nerve-centres themselves: at all events, a full dose of bromide very rapidly puts an end to them. At first the vessels of the nose, throat, and air-passages share in the spasm, and for a while the throat feels dry from the diminished secretion. But before long these vessels

I Read before the Harveian Society, Feb. 4th, 1886. pass from a condition of spasm into a condition of paralytic dilatation, and then commences the flux of liquid, copious and clear at first, but gradually growing more opaque as cellular elements become mixed with it, and finally diminishing. In catarrh primarily nasal the affected arteries are the terminal branches of the internal maxillary, the nasal or sphenopalatine, which supply the mucous membrane of the nose. Other offshoots of this artery may also be affected, and it is probable that the acute earache which is so common in young children in the early stage of a catarrb, long before any effects of Eustachian obstruction are manifested, is due to a tense hyperæmia of the drum membrane resulting from a paralytic dilatation of the tympanic branch of the internal maxillary. Nor is the congestion limited to this artery and its subdivisions; it may spread to other branches of the external carotid, and the facial may be felt forcibly beating. One consequence of the dilatation of the nasal branches of the internal maxillary is congestion of the highly vascular mucous membrane covering the inferior turbinated bones, the result of which is the production of a condition of extreme hyperæsthesia of this part, expressing itself partly by local sensations of tingling, and partly by the reflex neurosis known as " sneezing." The hyperæsthesia is often so great that a simple draught of cool air will at once excite this reflex process.

There is reason also to believe that an exaggerated sensibility of the mucous membrane covering the turbinated bones may not only be a consequence of catarrh, but may also rank among its causes. It is well known that in some persons the inhalation of air which contains dust of powdered ipecacuanha or pollen of certain grasses excites sneezing, asthmatic symptoms, and catarrh. This asthma is certainly a neurosis excited by the local irritation, and it is probable that the catarrh is of the same nature. Again, in cases of infectious catarrh, under which head may be included influenza, measles, and whooping-cough, it is not unlikely that the process is similar. Many ordinary catarrhs are distinctly contagious, as is known in every bousehold; and the contagium, whatever it be, probably causes at first local irritation and reflexly catarrh. Even in health a catarrhal flow will often be induced in susceptible persons by going out of a warm room into a very cold atmosphere on a wintry day.

The facts just quoted are sufficient to suggest from analogy the possibility of some cases of ordinary catarrh being due to "germs" of some kind. Of this nothing is certainly known. The chief arguments in its favour are the contagiousness of some catarrhs, the benefit which sometimes is obtained from the local use of antiseptic sprays or lotions containing quinine, salicylic acid, iodine, and similar substances, and from inhalacions of camphor, and, lastly, certain observations on the results of experimentally inhaling the air escaping from sewer-ventilators, which were thought to point in this direction. These arguments have no doubt a certain value, but to ascribe all catarrh to germs, as has recently been suggested, is surely to fly in the face of universal experience as to the connexion between an external chill and the catarrh which shortly follows it.

If it be true that catarrh is a reflex neurosis, it is clear that a treatment which is essentially diaphoretic must miss the mark. It is to neurotic remedies that we must look for alleviation and cure. The indications for treatment are three: we need to soothe the reflex disturbance of the central nervous system, to quiet the local congestion and hyperrsthesia of the nasal mucous membrane, and to arrest the flux, if it have already commenced.

The first indication may be to some extent met by the administration of opium. It is to the sedative influence of this drug on the nervous system, rather than to any diaphoretic action which may result, that Dover's powder owes its reputation in the treatment of catarrh. Laudanum sometimes is distinctly successful in arresting a cold. But the other effects of opium make it not altogether a desirable remedy. Chloral hydrate is free from these objectionable effects; but both opium and chloral are dangerous drugs, and they cannot be pushed with safety. Bromide of potassium is, however, free from these objections; it is by far the safest nervine sedative which we possess. Professor Wood says: "No case of acute poisoning in man with the bromide of potassium has been reported, and I have never seen a single dose of it produce any obvious effect." A case is recorded in which an epileptic idiot took at a single dose no less than two ounces and a half of this salt. No drowsiness was produced, and 